\title{
SEISMIC PERFORMANCE ASSESSMENT OF THE TORSIONAL EFFECT IN ASYMMETRIC STRUCTURES USING PUSHOVER AND NON-LINEAR TIME HISTORY METHOD
}

\author{
Nischith $S^{1}$, Avinash Gornale ${ }^{2}$, Sowjanya G V V $^{3}$, B G Naresh Kumar ${ }^{4}$ \\ ${ }^{l}$ PG Student, Dept. of Civil Engineering, Sri Siddhartha Institute of Technology, Tumkur District, Karnataka, India \\ ${ }^{2}$ Asst. Professor, Dept. of Civil Engineering, Maharaja Institute of Technology, Mysore District, Karnataka, India \\ ${ }^{3}$ Asst. Professor, Dept. of Civil Engineering, Sri Siddhartha Institute of Technology, Tumkur District, Karnataka, \\ India \\ ${ }^{4}$ Prof \& Principal, Dept. of Civil Engineering, Maharaja Institute of Technology, Mysore District, Karnataka, India
}

\begin{abstract}
In the recent time we come across many structures which are irregular in shape, this type of cannot be avoided due to the functional and architectural requirements. These type of structures have irregular distribution of centre of mass and centre of rigidity which causes the torsional effect on the structures which is one of the most important factor influencing the seismic damage of the structure. Structures with asymmetric distribution of mass and rigidity undergoes torsional motions during earthquake. To assess the torsional effect on the structures in the present study four types of structures are considered with varying eccentricity subjected to Pushover Analysis and Non-Linear Time History Analysis. The performance of the structures are assessed as per the procedure prescribe in ATC-40 and FEMA-356. The analysis of the structural models is done in ETABS. The results have shown that the structures with less eccentricity and in the direction of the columns orientation are performing well, also ductility, drift, and lateral displacement depends on the eccentricity of the structures.
\end{abstract}

Key Words: Symmetric Structure, Asymmetric Structure, Pushover Analysis, Non-Linear Time History Analysis. $* * *$

\section{INTRODUCTION}

Earthquake is a manifestation of rapid release of stress waves during a brittle rupture of rock. The complexity of earthquake ground motion is primarily due to factors such as source effect, path effect and local site effect. Earthquake causes ground to vibrate and structures supported on ground in turn are subjected to this motion. Thus the dynamic loading on the structure during an earthquake is not external loading, but due to motion of support. The various factors contributing to the structural damage during earthquake are vertical irregularities, irregularity in strength and stiffness, mass irregularity, torsional irregularity etc.

\subsection{Symmetric and Asymmetric Structures}

Asymmetric structures are almost unavoidable in present day construction due to the functional and architectural requirements. In Asymmetric structures, the lateral torsional coupling due to eccentricity between Centre of Mass (CM) and Centre of Rigidity (CR) generates torsional vibration even under purely translational ground shaking. During shaking inertial forces act through the centre of mass (CM) and the resistive forces act through the centre of rigidity (CR) due to this non-concurrency of these points inertial force and resistive force induces twisting of the structure in additional to the lateral vibration. ${ }^{[5]}$ Dr.Tande, S.B.Kadam

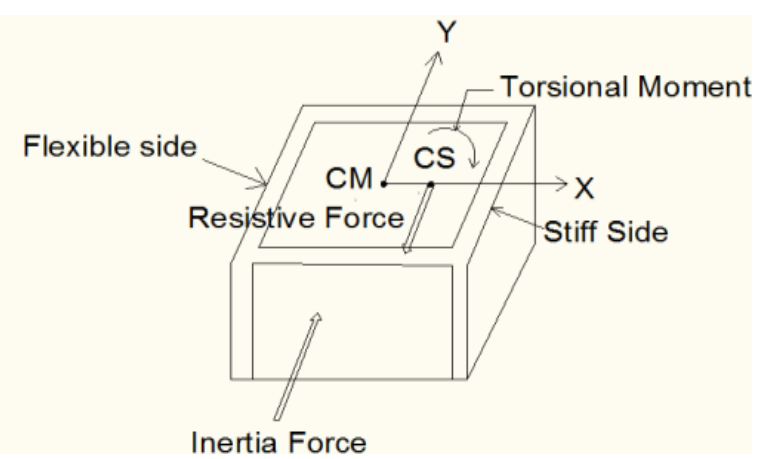

Fig 1: Generation of Torsional Moment in Asymmetric Structures.

\section{a) Symmetric Structures:}

Structures where the centre of mass coincides with the centre of resistance are called symmetric structures. In this type of structures the eccentricity will be zero i.e. centre of mass and centre of resistance is at the centre, it is difficult to obtain these type of structures everywhere due to aesthetical conditions, architectural and functional requirements. The strength and the stiffness will be equally distributed. Seismic effect on these types of structures is very less.

\section{b) Asymmetric Structures:}

Structures where the centre of mass does not coincide with the centre of resistance are called asymmetric structures. In this type of structures eccentricity exists i.e. centre of mass does not coincide with centre of resistance. Due to the 
architectural and functional requirement this type of structures are gaining popularity. During an earthquake building with an asymmetric distribution of strength and stiffness undergo coupled lateral and torsional motions.

\section{SEISMIC PERFORMANCE EVALUATION OF}

\section{STRUCTURES}

Buildings subjected to earthquake ground motions undergo varying oscillatory motions, which may cause failure or major structural damage. The performance evaluation based approach is an alternative to that approach, which is based on quantifying the inelastic deformations of the members and the building as a whole, under the seismic loads. The deformations or strains are considered to be better measures than stresses or forces to assess damage. Thus, such a configuration induces a torsional moment that in turn invokes torsional rotation of the floor diaphragm.

The seismic performance of a building is measured by the state of damage under a certain level of seismic hazard. The state of damage is quantified by the drift of the roof and the displacement of the structural elements. Pushover analysis and Non-Linear Time History Analysis gives an insight into the maximum base shear that the structure is capable of resisting. ${ }^{[4]}$ Rama Raju K, Cinitha A

\subsection{Pushover Analysis}

Pushover analysis is defined as an analysis where a mathematical model directly incorporating the nonlinear load-deformation characteristics of individual components and elements of the structure shall be subjected to monotonically increasing lateral loads representing inertia forces of an earthquake until a target displacement is reached. Target displacement is the maximum displacement of the structure at top expected under applied earthquake ground motion. Pushover analysis is conducted to find out the performance points that are Immediate Occupancy, Life Safety, and Collapse Prevention of symmetric and asymmetric structures using static pushover curve.

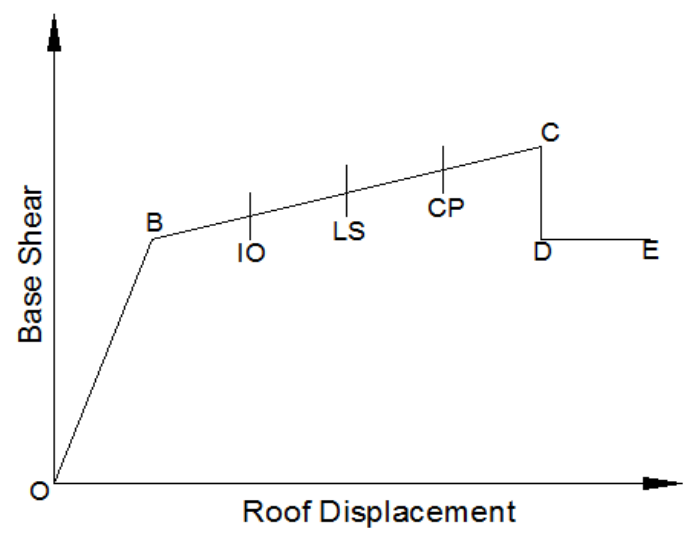

Fig 2: Static Pushover Curve
Response characteristics that can be obtained from the pushover analysis are summarized as follows:

a) Estimates force and displacement capacities of the structure and sequence of the member yielding and the progress of the overall capacity curve.

b) Estimates force demands on potentially brittle elements and deformation demands on ductile elements.

c) Estimates target displacement demand, corresponding inter-storey drift.

d) Identification of the critical regions, where the inelastic deformations are expected to be high and identification of strength irregularities of the structure.

\subsection{Non-Linear Time History Analysis.}

The time history analysis is an actual dynamic analysis that can be done for both linear and nonlinear systems. It is found that this analysis incorporates the real time earthquake ground motions and gives the true picture of the possible deformation and collapse mechanism in a structure. But, at the same time, it is a very tedious and complex analysis having a lot of mathematical calculations. Although nonlinear dynamic analysis is generally considered to be the most accurate of the available analysis methods, it is cumbersome for design. This is the most sophisticated analysis procedure for predicting forces and displacements under seismic input. ${ }^{[6]} \mathrm{G} S$ Hiremath and Kushappa M Kabade

\section{DESCRIPTION OF MODELS}

\section{Model-1: Sym Structure}

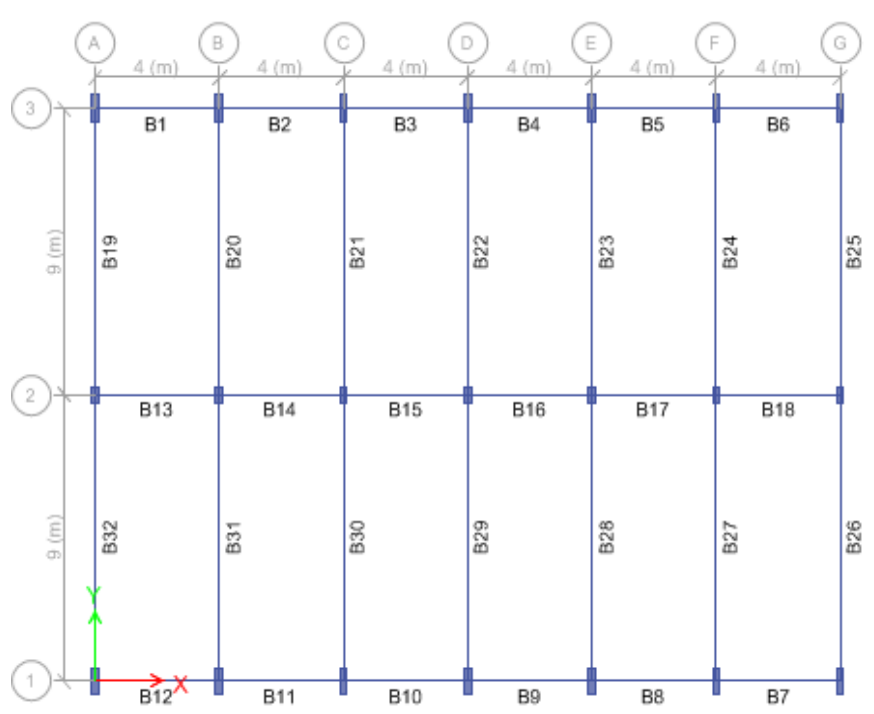

Fig 3: Plan of SYM Structure. 
Table 1: Seismic details of the Structures.

\begin{tabular}{|c|c|c|}
\hline Type of Structures & \multicolumn{2}{|c|}{ Multi-Storey RC Building } \\
\hline Number of Stories & \multicolumn{2}{|c|}{$\mathrm{G}+8$} \\
\hline \multirow{2}{*}{ Materials } & Concrete & M25 \\
\cline { 2 - 3 } & Steel & Fe415 \\
\hline Slab Section & Slab & $125 \mathrm{~mm}$ \\
\hline $\begin{array}{c}\text { Zonal } \\
\text { Considerations }\end{array}$ & Soil Type & II \\
\cline { 2 - 3 } & Zone & IV \\
\cline { 2 - 3 } & $\begin{array}{c}\text { Importance } \\
\text { factor }\end{array}$ & 1 \\
\cline { 2 - 3 } & $\begin{array}{c}\text { Reduction } \\
\text { Factor }\end{array}$ \\
\cline { 2 - 3 } & Zone Factor & 3 \\
\hline Live Load & $3 \mathrm{kN} / \mathrm{m}^{2}$ \\
\hline
\end{tabular}

Table 2: Details of SYM Structure

\begin{tabular}{|c|c|c|}
\hline \multirow{3}{*}{ Frame Sections } & Beam-1 & 230X450 mm \\
\cline { 2 - 3 } & Beam-2 & $230 X 850 \mathrm{~mm}$ \\
\cline { 2 - 3 } & Column-1 & $230 X 850 \mathrm{~mm}$ \\
\cline { 2 - 3 } & Column-2 & $230 X 500 \mathrm{~mm}$ \\
\hline Eccentricity & $\mathrm{e}_{\mathrm{x}}=0 \%$ & $\mathrm{e}_{\mathrm{y}}=0 \%$ \\
\hline
\end{tabular}

\section{Model-2: Asym-1 Structure}

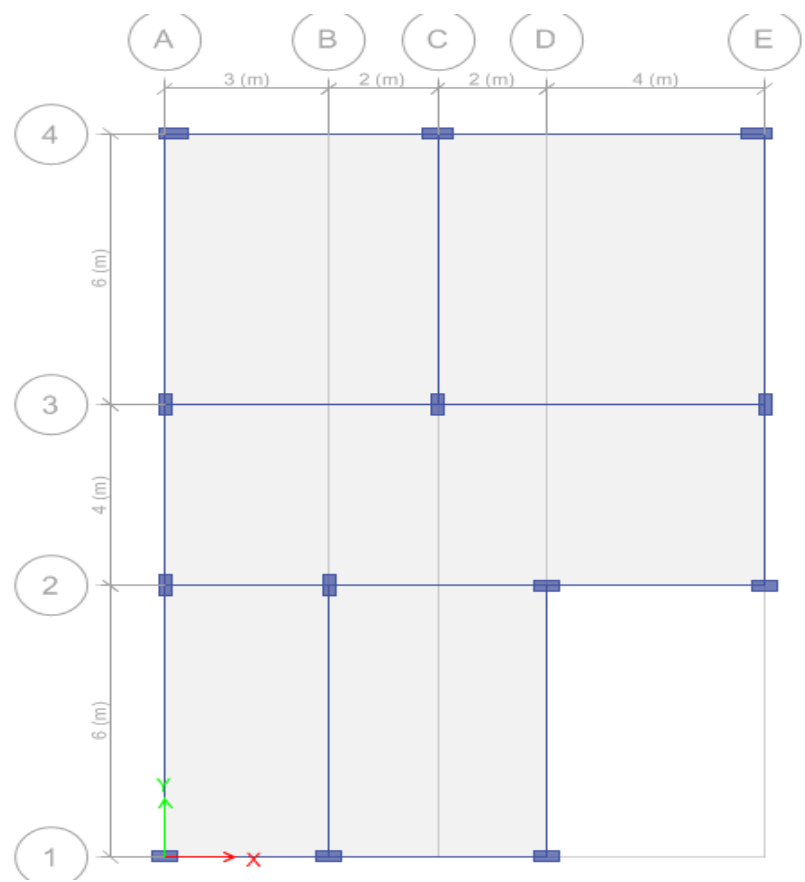

Fig 4: Plan of ASYM-1 Structure.

Table 3: Details of ASYM-1 Structure.

\begin{tabular}{|c|c|c|}
\hline \multirow{3}{*}{ Frame Sections } & Beam-1 & $230 X 400 \mathrm{~mm}$ \\
\cline { 2 - 3 } & Beam-2 & $230 X 550 \mathrm{~mm}$ \\
\cline { 2 - 3 } & Column-1 & $230 X 450 \mathrm{~mm}$ \\
\cline { 2 - 3 } & Column-2 & $230 \times 550 \mathrm{~mm}$ \\
\hline Eccentricity & $\mathrm{e}_{\mathrm{x}}=5 \%$ & $\mathrm{e}_{\mathrm{y}}=4.33 \%$ \\
\hline
\end{tabular}

\section{Model-3: Asym-2 Structure}

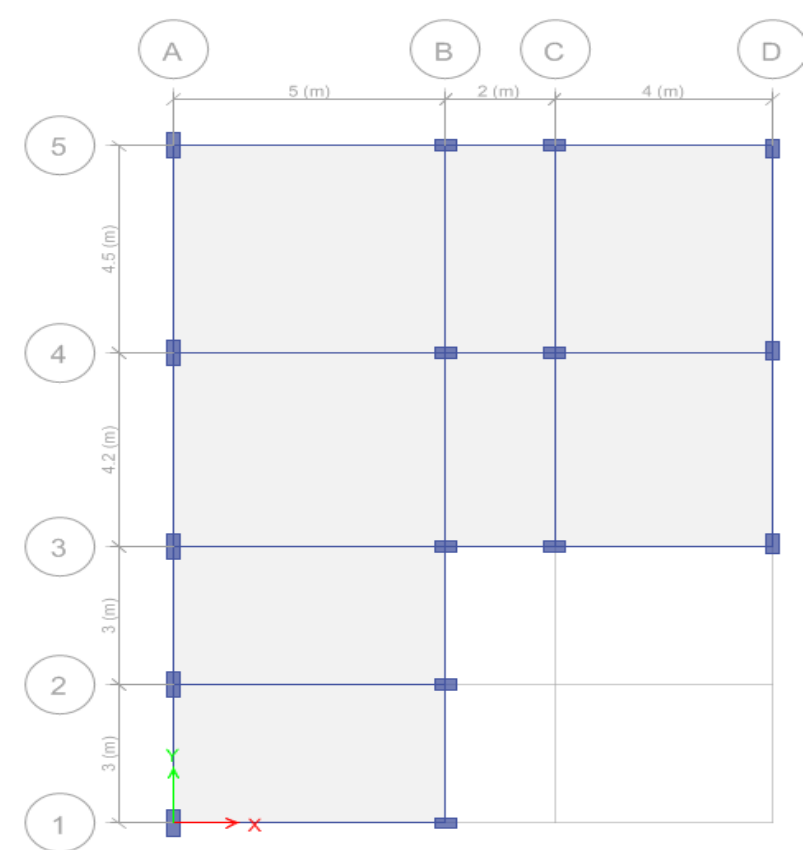

Fig 5: Plan of ASYM-2 Structure.

Table 4: Details of ASYM-2 Structure.

\begin{tabular}{|c|c|c|}
\hline \multirow{2}{*}{ Frame Sections } & Beam-1 & 230X500 mm \\
\cline { 2 - 3 } & Column-1 & 230X400 mm \\
\cline { 2 - 3 } & Column- 2 & $230 X 550 \mathrm{~mm}$ \\
\hline Eccentricity & $\mathrm{e}_{\mathrm{x}}=14 \%$ & $\mathrm{e}_{\mathrm{y}}=0.06 \%$ \\
\hline
\end{tabular}

\section{Model-4: Asym-3 Structure.}

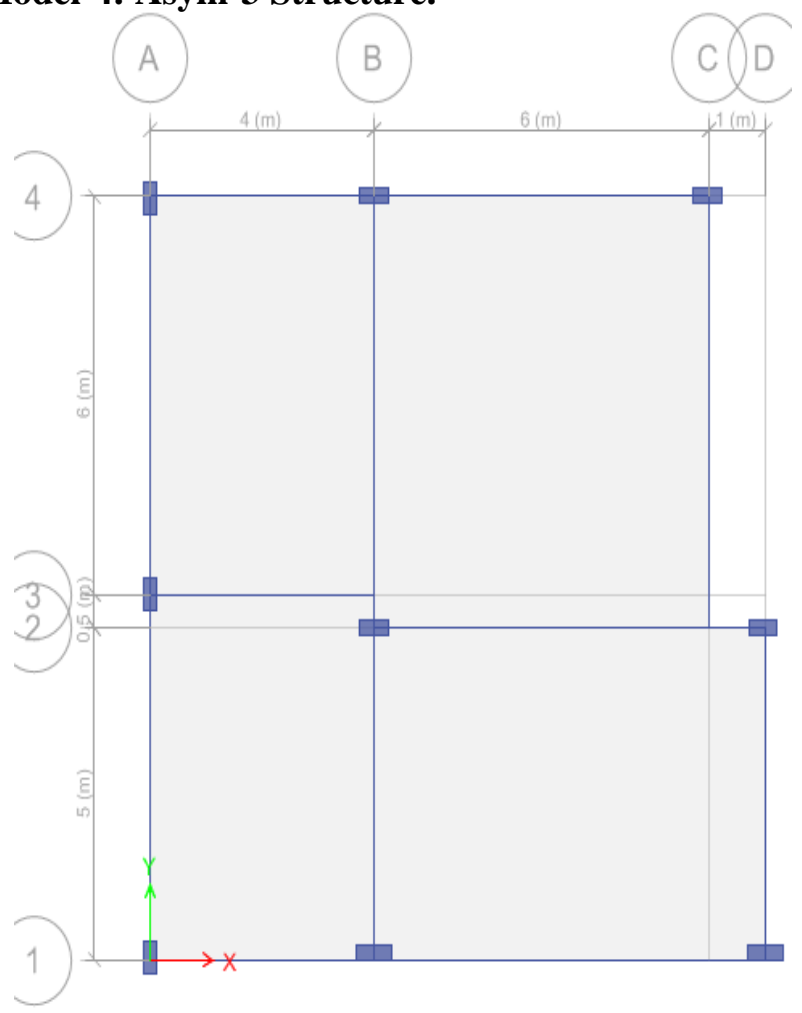

Fig 6: Plan of ASYM-3 Structure. 
Table 5: Details of ASYM-3 Structure.

\begin{tabular}{|c|c|c|}
\hline \multirow{2}{*}{ Frame Sections } & Beam-1 & 230 X600 mm \\
\cline { 2 - 3 } & Column-1 & $230 \times 500 \mathrm{~mm}$ \\
\cline { 2 - 3 } & Column-2 & $230 \times 650 \mathrm{~mm}$ \\
\hline Eccentricity & $\mathrm{e}_{\mathrm{x}}=20 \%$ & $\mathrm{e}_{\mathrm{y}}=1.25 \%$ \\
\hline
\end{tabular}

\section{RESULTS AND DISCUSSIONS}

\subsection{PUSHOVER ANALYSIS}

\subsubsection{Base Shear and Roof Displacement Graph:}

The graph of Base Shear v/s Displacement is obtained by Non-linear Static Analysis i.e. Pushover Analysis which involves incrementally applying the calculated lateral load on Symmetric and Asymmetric structure till it fails to withstand the applied lateral load. The values of Base Shear and Displacement obtained by Pushover Analysis in Xdirection and $\mathrm{Y}$-direction are tabulated below and shown in graphs.

Table 6: Base Shear v/s Roof Displacement in X-Direction.

\begin{tabular}{|c|c|c|c|}
\hline Model & $\begin{array}{c}\text { Design } \\
\text { Base } \\
\text { Shear } \mathrm{V}_{\mathrm{B}} \\
(\mathrm{kN})\end{array}$ & $\begin{array}{c}\text { Base } \\
\text { Shear } \\
\text { in } \mathrm{kN}\end{array}$ & $\begin{array}{c}\text { Roof } \\
\text { Displacement in } \\
\mathrm{mm}\end{array}$ \\
\hline SYM & 2309.76 & 1530.10 & 308.10 \\
\hline ASYM-1 & 888.41 & 1254.06 & 381.40 \\
\hline ASYM-2 & 884.71 & 1368.07 & 356.10 \\
\hline ASYM-3 & 741.61 & 668.30 & 240.90 \\
\hline
\end{tabular}

Table 7: Base Shear v/s Roof Displacement in Y-Direction.

\begin{tabular}{|c|c|c|c|}
\hline Model & $\begin{array}{c}\text { Design } \\
\text { Base Shear } \\
\mathrm{V}_{\mathrm{B}}(\mathrm{kN})\end{array}$ & $\begin{array}{c}\text { Base } \\
\text { Shear } \\
\text { in } \mathrm{kN}\end{array}$ & $\begin{array}{c}\text { Roof } \\
\text { Displacement in } \\
\mathrm{mm}\end{array}$ \\
\hline SYM & 2309.76 & 3611.22 & 385.8 \\
\hline ASYM-1 & 888.41 & 1244.85 & 429.40 \\
\hline ASYM-2 & 884.71 & 1876.65 & 374.50 \\
\hline ASYM-3 & 741.61 & 478.96 & 110.70 \\
\hline
\end{tabular}

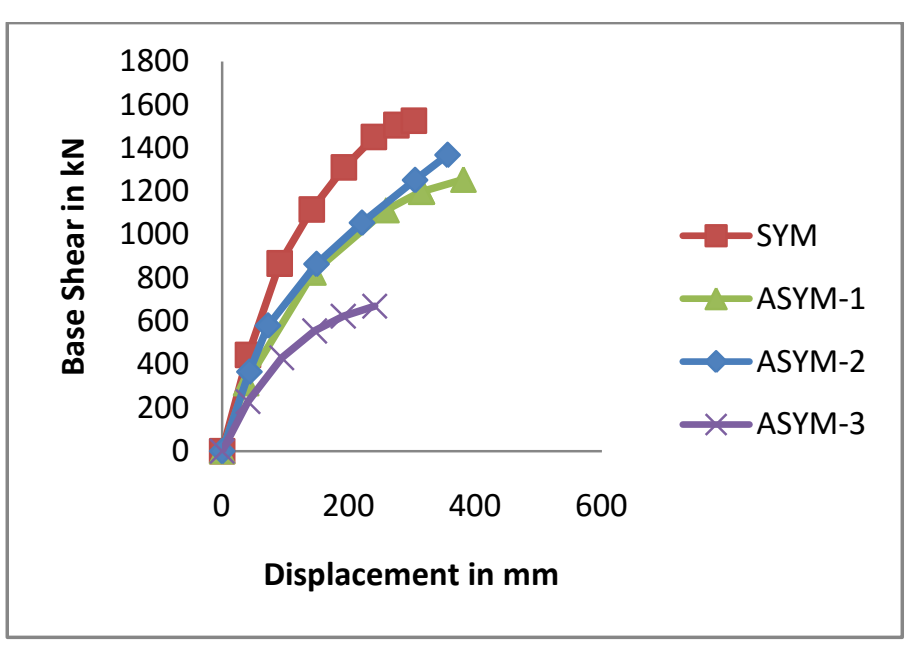

Fig 7: Pushover Curve in X-Direction.



Fig 8: Pushover Curve in Y-Direction

From the above Tables 6 and 7, it is observed that the lateral load resisting capacity of the SYM structure is lesser by $33.77 \%$, ASYM-1 is greater by $41.15 \%$, ASYM-2 is greater by $54.63 \%$ and ASYM-3 is lesser by $10 \%$ in X-direction.

Also the lateral load resisting capacity of the SYM structure is greater by $53.05 \%$, ASYM-1 is greater by $40.12 \%$, ASYM-2 is greater by $112.12 \%$ and ASYM-3 is lesser by $35.41 \%$ Y-direction.

The Symmetric structure has the greater lateral load resisting capacity in $\mathrm{Y}$-direction than in the $\mathrm{X}$-direction this is because all the columns are oriented in Y-direction, both Asymmetrical-1 and Asymmetrical-2 can withstand base shear greater than that of the design base shear.Asymmetrical-3 has the lower lateral load resisting capacity than that of the design base shear because of the highest eccentricity provided.

\subsubsection{Lateral Displacements:}

This represents the displacement of Centre of Mass from its point of acting due to the applied lateral loads. The maximum displacement of all the SYM and ASYM structures at each floor with respect to ground floor in $\mathrm{X}$ direction and Y-direction obtained from Pushover analysis are shown in graphs and tables representing maximum displacements.

Table 8: Maximum Lateral Displacement in XDirection.

\begin{tabular}{|c|c|c|}
\hline Model & Storey & $\begin{array}{c}\text { Displacement in } \\
\mathrm{mm}\end{array}$ \\
\hline SYM & Top Storey & 308.10 \\
\hline ASYM-1 & Top Storey & 387.70 \\
\hline ASYM-2 & Top Storey & 357.90 \\
\hline ASYM-3 & Top Storey & 237.50 \\
\hline
\end{tabular}


Table 9: Maximum Lateral Displacement in YDirection.

\begin{tabular}{|c|c|c|}
\hline Model & Storey & $\begin{array}{c}\text { Displacement in } \\
\mathrm{mm}\end{array}$ \\
\hline SYM & Top Storey & 385.80 \\
\hline ASYM-1 & Top Storey & 429.40 \\
\hline ASYM-2 & Top Storey & 456.90 \\
\hline ASYM-3 & Top Storey & 166.80 \\
\hline
\end{tabular}

From the table 8 and 9, the lateral displacement w.r.t. SYM structure, ASYM-1 increases by $25.83 \%$, ASYM-2 increases by $16.16 \%$ and ASYM-3 reduces by $22.91 \%$ in X-direction.

Similarly, lateral displacement w.r.t. SYM structure, ASYM-1 increases by $11.30 \%$, ASYM-2 increases by $18.42 \%$ and ASYM-3 reduces by $56.76 \%$ in Y-direction.

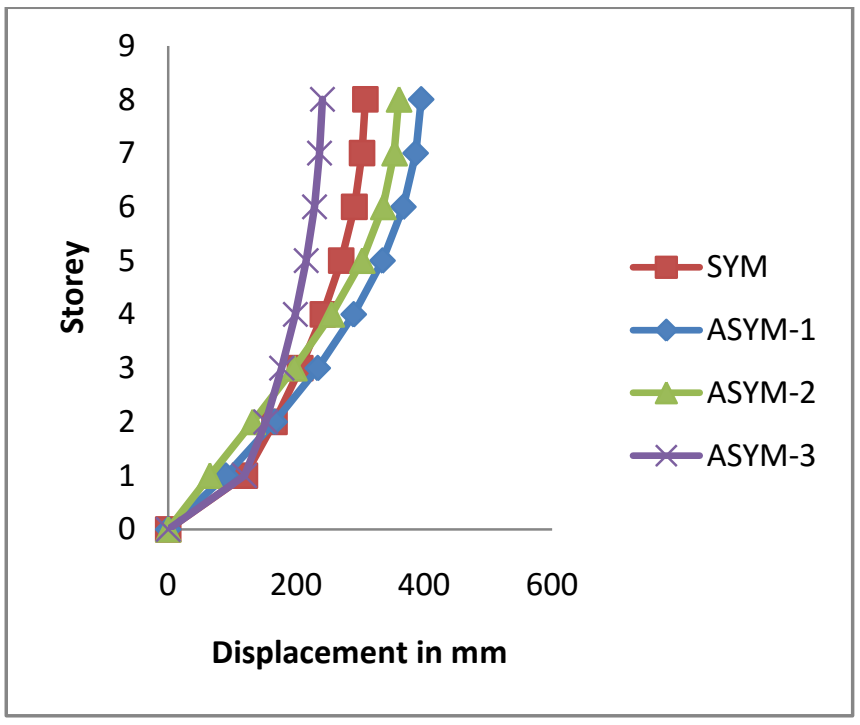

Fig 9: Lateral Displacement of Roof in X-Direction.

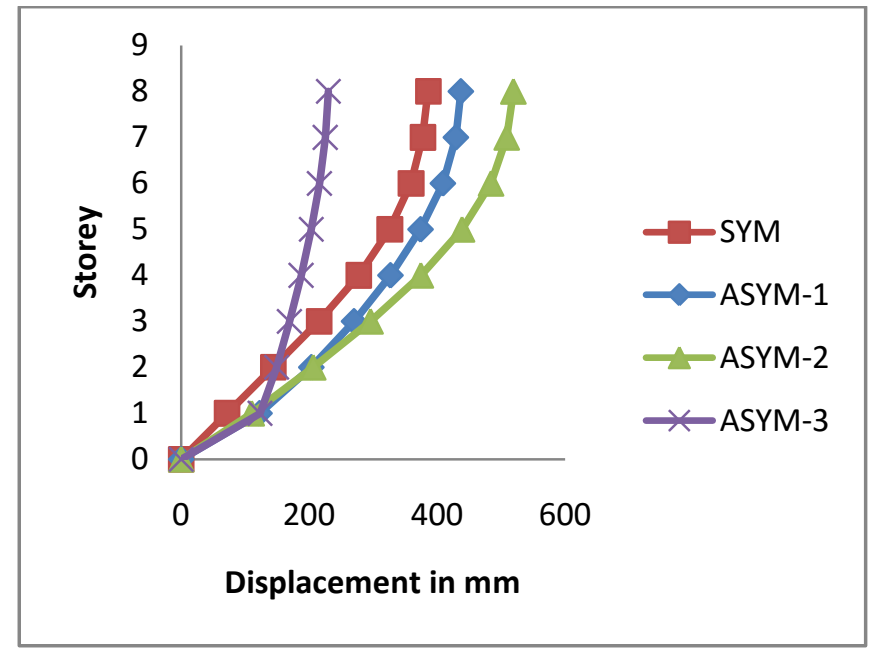

Fig 10: Lateral Displacement of Roof in Y-Direction.
1 and ASYM-2 is greater in Y-direction and ASYM-3 in Xdirection.

\subsubsection{Ductility Ratio}

Ductility of the structure is the capacity to undergo large inelastic deformation without significant loss of strength or stiffness of the structure. If the structure is non-ductile in nature the structure will collapse without yielding. Reinforced Concrete structures for seismic resistance must be designed, detailed and constructed in such a way that the ductility factor should be at least equal to 3 up to the point of beginning of visible damage or even greater, to point of beginning of structural damage. The ductility ratio of Symmetric and Asymmetric structures analyzed is tabulated.

Table 10: Ductility Ratio in X-Direction.

\begin{tabular}{|c|c|c|c|}
\hline Model & $\Delta y$ & $\Delta \max$ & $\mu$ \\
\hline SYM & 166 & 308.10 & 1.85 \\
\hline ASYM-1 & 88.90 & 387.70 & 4.36 \\
\hline ASYM-2 & 130.60 & 357.90 & 2.74 \\
\hline ASYM-3 & 102.90 & 237.50 & 1.69 \\
\hline
\end{tabular}

Table 11: Ductility Ratio in Y-Direction.

\begin{tabular}{|c|c|c|c|}
\hline Model & $\Delta y$ & $\Delta \max$ & $\mu$ \\
\hline SYM & 142.70 & 384.50 & 2.69 \\
\hline ASYM-1 & 119.40 & 429.40 & 3.59 \\
\hline ASYM-2 & 96.40 & 456.90 & 4.73 \\
\hline ASYM-3 & 98.50 & 166.80 & 1.69 \\
\hline
\end{tabular}

Table 10 and 11, Symmetric structure is more ductile in $\mathrm{Y}$ direction compared to that of in $\mathrm{X}$-direction because all the columns are oriented in $\mathrm{Y}$ - direction, Asymmetrical-1 is more ductile in $\mathrm{X}$-direction when compared to that of $\mathrm{Y}$ direction with a maximum displacement of $387.70 \mathrm{~mm}$, Asymmetrical-2 is more ductile in Y-direction when compared to that of $\mathrm{X}$-direction with a maximum displacement of $456.90 \mathrm{~mm}$ and Asymmetrical-3 with identical ductility ratio value fails at a displacement of $166.80 \mathrm{~mm}$ in Y-direction.

\subsubsection{Maximum Storey Drifts}

Story drift is the difference in lateral deflection between two adjacent stories of the structure. Drift affects both the structural elements that are part of the lateral force resisting system and structural elements that are not part of the lateral force resisting system. Drifts obtained from Pushover analysis is tabulated and shown in graph.

Table 12: Maximum Storey Drift in X-Direction.

\begin{tabular}{|c|c|c|}
\hline Model & Storey & Drift \\
\hline SYM & 1st Storey & 0.0286 \\
\hline ASYM-1 & 1st Storey & 0.0213 \\
\hline ASYM-2 & 2nd Storey & 0.0191 \\
\hline ASYM-3 & 1st Storey & 0.0284 \\
\hline
\end{tabular}

The lateral displacement for SYM structure is greater in Ydirection than in $\mathrm{X}$-direction because all the columns are oriented in Y-direction. The lateral displacement for ASYM- 
Table 13: Maximum Storey Drift in Y-Direction.

\begin{tabular}{|c|c|c|}
\hline Model & Storey & Drift \\
\hline SYM & 3rd Storey & 0.0202 \\
\hline ASYM-1 & 1st Storey & 0.0291 \\
\hline ASYM-2 & 2nd Storey & 0.0274 \\
\hline ASYM-3 & 1st Storey & 0.0292 \\
\hline
\end{tabular}

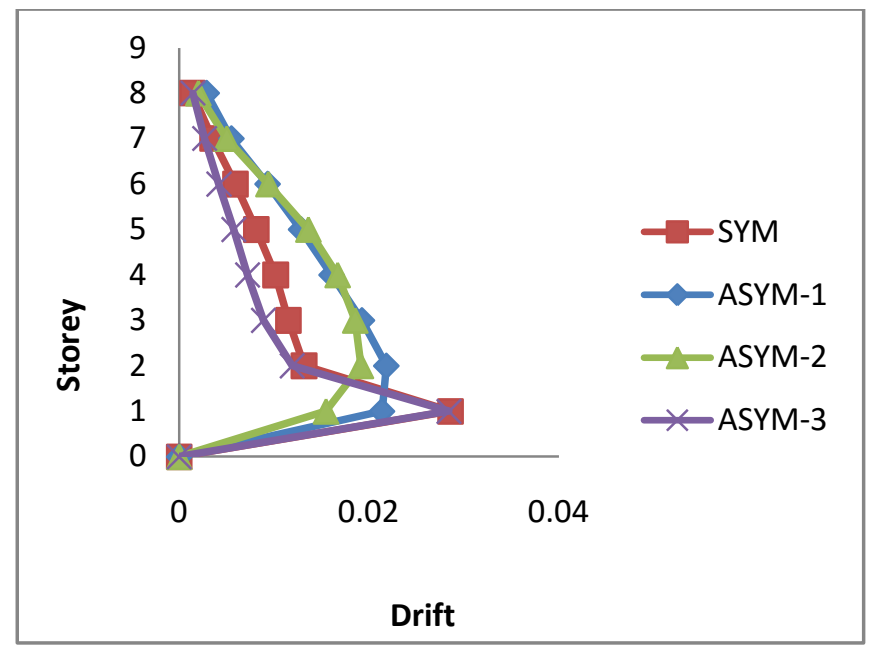

Fig 11: Maximum Storey Drift in X-Direction.

From Table 12, it is evident that the SYM and ASYM-3 have almost equal values of drift, followed by ASYM-1 and ASYM-2 has a lesser drift compared to all the other structures in 1st storey, also its drift is greater in 2nd storey in X-direction.

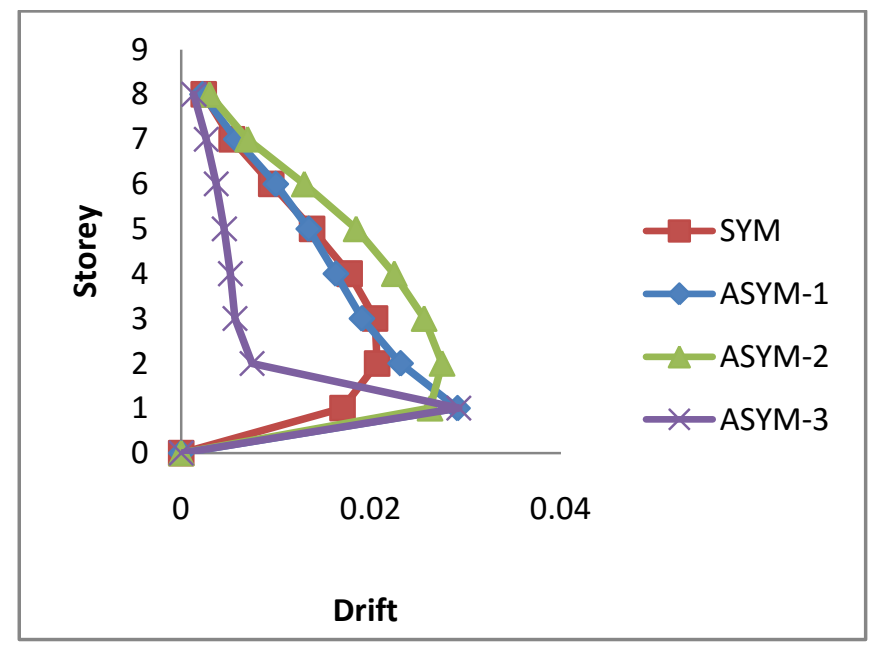

Fig 12: Maximum Storey Drift in Y-Direction.

From Table 13, SYM structure has a maximum drift in 3rd storey, ASYM-1 has a maximum drift in 1st strorey, ASYM-2 has a maximum drift in 2nd storey and ASYM-3 has a maximum drift in 1 st storey in Y-direction.

From above it can be seen that SYM structure is performing well in Y-direction with its maximum drift in 3rd storey, ASYM-1 in Y-direction, ASYM-2 in Y-direction and ASYM-3 have almost equal values of drift in both the direction.

\subsubsection{Target Displacement Point.}

Target displacement point defines the maximum base shear the structure can withstand at the point of yielding of the structure, also the displacement the corresponding structure will undergo when subjected to Pushover analysis.

Table 14: Target Displacement Results in X-Direction.

\begin{tabular}{|c|c|c|}
\hline Model & Shear in $\mathrm{kN}$ & $\begin{array}{c}\text { Displacement in } \\
\mathrm{mm}\end{array}$ \\
\hline SYM & 1184.94 & 159.80 \\
\hline ASYM-1 & 553.25 & 87.60 \\
\hline ASYM-2 & 633.63 & 86.80 \\
\hline ASYM-3 & 474.63 & 112.60 \\
\hline
\end{tabular}

Table 15: Target Displacement Results in Y-Direction.

\begin{tabular}{|c|c|c|}
\hline Model & Shear in $\mathrm{kN}$ & $\begin{array}{c}\text { Displacement in } \\
\mathrm{mm}\end{array}$ \\
\hline SYM & 1807.20 & 50.20 \\
\hline ASYM-1 & 554.57 & 109.20 \\
\hline ASYM-2 & 684.87 & 57.90 \\
\hline ASYM-3 & 478.96 & 120.60 \\
\hline
\end{tabular}

From Table 14 and 15, SYM structure performs well in Ydirection with greater base shear resistance and minimum displacement, ASYM-1performs well in Y-direction almost with equal base shear acting but more ductile in $\mathrm{Y}$-direction, ASYM-2 performs well in Y-direction with greater base shear and lesser displacement and ASYM-3 have almost equal value of base shear and displacement performs badly to the seismic loading compared to all the structures in both the directions.

\subsection{NON-LINEAR TIME HISTORY ANALYSIS}

\subsubsection{Maximum Storey Displacement}

This represents the maximum displacement of the roof from its position due to he applied seismic loading on the structure. Performance of the structure due to he applied seismic loading can be assessed.

Table 16: Maximum Storey Displacement in X-Direction.

\begin{tabular}{|c|c|c|}
\hline Model & Storey & $\begin{array}{c}\text { Displacement in } \\
\mathrm{mm}\end{array}$ \\
\hline SYM & 2nd Storey & 80.10 \\
\hline ASYM-1 & 1st Storey & 2421.00 \\
\hline ASYM-2 & 5th Storey & 1072.00 \\
\hline ASYM-3 & 1st Storey & 1364.70 \\
\hline
\end{tabular}

Table 17: Maximum Storey Displacement in Y-Direction.

\begin{tabular}{|c|c|c|}
\hline Model & Storey & $\begin{array}{c}\text { Displacement in } \\
\mathrm{mm}\end{array}$ \\
\hline SYM & 2nd Storey & 102.90 \\
\hline ASYM-1 & 5th Storey & 1000.30 \\
\hline ASYM-2 & Top Storey & 382.30 \\
\hline ASYM-3 & 5th Storey & 1558.40 \\
\hline
\end{tabular}




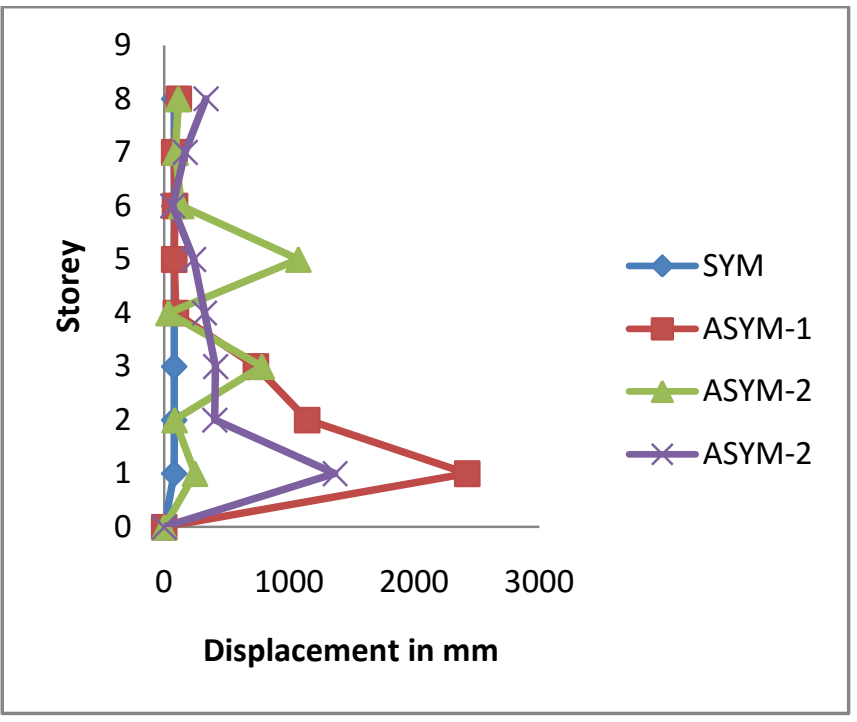

Fig 13: Maximum Storey Displacement in X-Direction.



Fig 14: Maximum Storey Displacement in Y-Direction.

From Table 16, it can be observed as the eccentricity increases that the maximum storey displacement compared to that of SYM structure, ASYM-1 has 30 times more displacement, ASYM-2 has 14 times more displacement, and ASYM-3 has 18 times more displacement in Xdirection.

Similarly from Table 17, the maximum storey displacement compared to that of SYM structure, ASYM-1 has 10 times more displacement, ASYM-2 has 4 times more displacement and Asymmterical-3 has 16 times more displacement in $\mathrm{Y}$ direction.

It can be observed that the SYM structure is performing well in $\mathrm{Y}$-direction than in that of $\mathrm{X}$-direction, ASYM-1 is performing well in $\mathrm{Y}$-direction than in $\mathrm{X}$-direction, and ASYM-2 is performing well in $Y$-direction than in $\mathrm{X}$ direction and ASYM-3 has almost equal values of displacements in both the directions leading to the brittle failure of the structure.

\subsubsection{Lateral Displacements of Roof}

This is the displacement of Centre of Mass from its point of acting. The maximum displacement of all the symmetrical and asymmetrical structures at each floor with respect to ground floor in X-direction and Y-direction obtained from Non-linear Time History analysis are shown in graphs and tables representing maximum lateral displacements of roof.

Table 18: Lateral Displacement of Roof in X-Direction.

\begin{tabular}{|c|c|c|}
\hline Model & Storey & $\begin{array}{c}\text { Displacement in } \\
\mathrm{mm}\end{array}$ \\
\hline SYM & 2nd Storey & -80.10 \\
\hline ASYM-1 & 1st Storey & 1244.10 \\
\hline ASYM-2 & 5th Storey & -192.30 \\
\hline ASYM-3 & 1st Storey & -941.80 \\
\hline
\end{tabular}

Table 19: Lateral Displacement of Roof in Y-Direction.

\begin{tabular}{|c|c|c|}
\hline Model & Storey & $\begin{array}{c}\text { Displacement in } \\
\mathrm{mm}\end{array}$ \\
\hline SYM & 2nd Storey & -102.90 \\
\hline ASYM-1 & 7th Storey & -512.50 \\
\hline ASYM-2 & Top Storey & -91.40 \\
\hline ASYM-3 & 4th Storey & 1028.70 \\
\hline
\end{tabular}

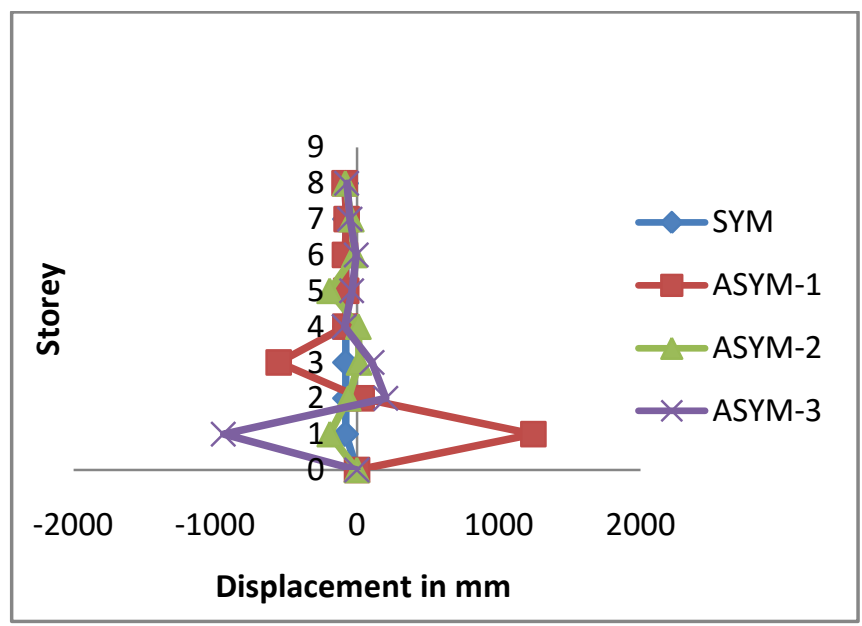

Fig 15: Lateral Displacement of Roof in X-Direction.

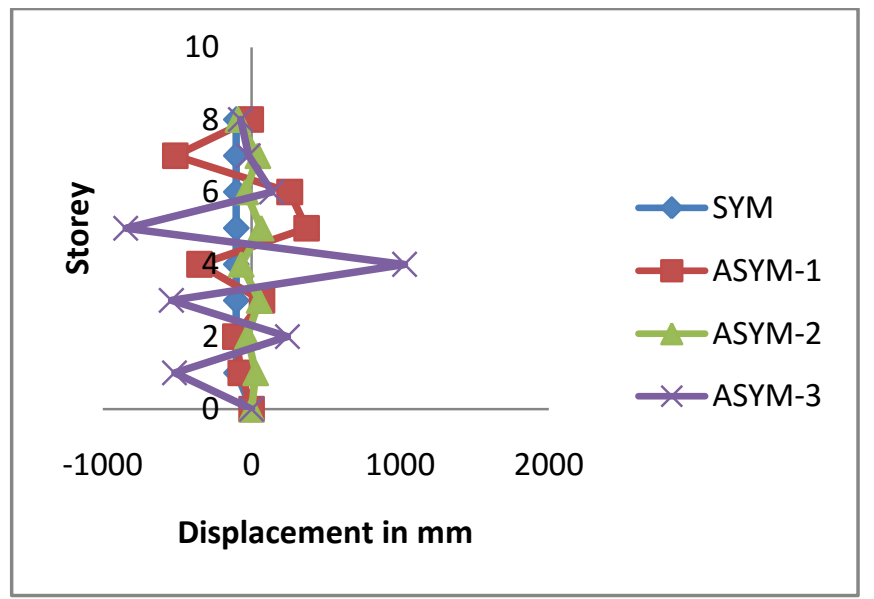

Fig 16: Lateral Displacement of Roof in Y-Direction. 
From Table18, It can be observed that as the eccentricity increases that the maximum storey displacement compared to that of SYM structure, ASYM-1 has 16 times more displacement, ASYM-2 has 2.5 times more displacement, and ASYM-3 has 12 times more displacement in Xdirection.

From Table 19, It can be observed that as the eccentricity increases that the maximum storey displacement compared to that of SYM structure, ASYM-1 has 5 times more displacement, ASYM-2 has less displacement, and ASYM-3 has 10 times more displacement in Y-direction.

\subsubsection{Maximum Storey Drifts.}

Story drift is the difference in lateral deflection between two adjacent stories of the structure. Drift affects both the structural elements that are part of the lateral force resisting system and structural elements that are not part of the lateral force resisting system. Drifts obtained from Pushover analysis is tabulated and shown in graph.

Table 20: Maximum Storey Drift in X-Direction.

\begin{tabular}{|c|c|c|}
\hline Model & Storey & Drift \\
\hline SYM & 1st Storey & 0.0190 \\
\hline ASYM-1 & 2nd Storey & 0.9454 \\
\hline ASYM-2 & 6th Storey & 0.3450 \\
\hline ASYM-3 & 2nd Storey & 0.8677 \\
\hline
\end{tabular}

Table 21: Maximum Storey Drift in Y-Direction.

\begin{tabular}{|c|c|c|}
\hline Model & Storey & Drift \\
\hline SYM & 1st Storey & 0.0240 \\
\hline ASYM-1 & 5th Storey & 0.3647 \\
\hline ASYM-2 & 8th Storey & 0.1546 \\
\hline ASYM-3 & 4th Storey & 0.8884 \\
\hline
\end{tabular}

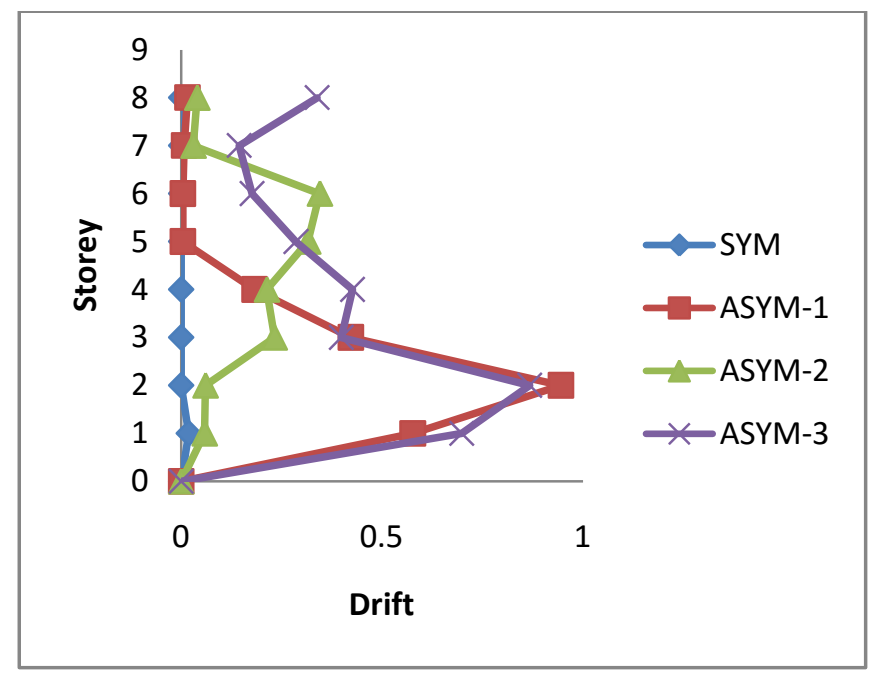

Fig 17: Maximum Storey Drift in X-Direction.

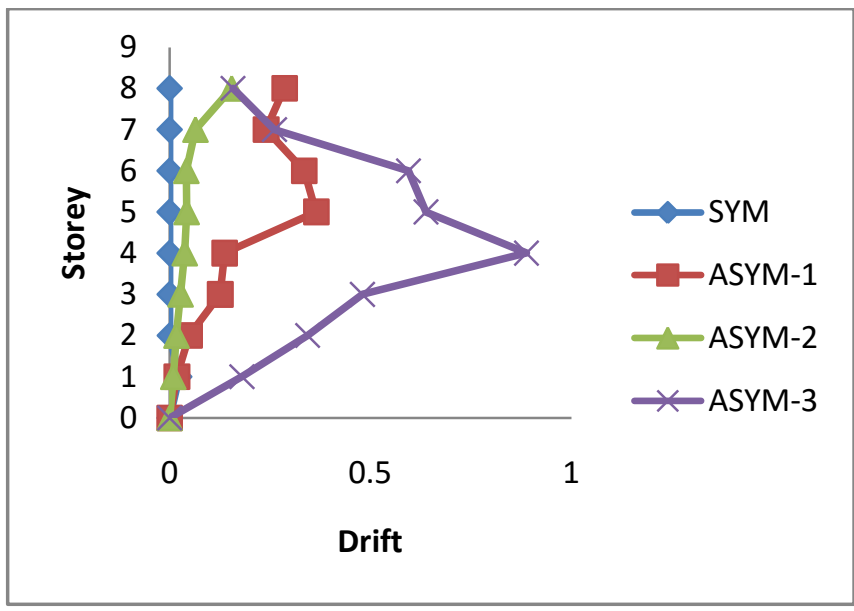

Fig 18: Maximum Storey Drift in Y-Direction

From Table 20 and 21, it can be seen that SYM structure is performing well in both $\mathrm{X}$ and $\mathrm{Y}$-direction with its minimum drift in 1st storey, ASYM-1 with maximum drift at 5th storey in Y-direction, ASYM-2 with maximum drift at 8th storey in Y-direction and ASYM-3 has almost equal value of drift in both $\mathrm{X}$ and $\mathrm{Y}$-directions.

\subsubsection{Spectral Displacement v/s Period.}

This represents the maximum or peak response of a single degree of freedom system to a particular seismic input as a function of natural frequency. The tables represents the spectral displacement of the SYM and ASYM structures in $\mathrm{X}$ and $\mathrm{Y}$-directions and its corresponding graphs.

Table 22: Spectral Displacement in X-Direction.

\begin{tabular}{|c|c|c|}
\hline Model & $\begin{array}{c}\text { Period } \\
\text { in sec }\end{array}$ & $\begin{array}{c}\text { Spectral } \\
\text { Displacement } \\
\text { in mm }\end{array}$ \\
\hline SYM & 1.429 & 456.20 \\
\hline ASYM-1 & 1.429 & 245.00 \\
\hline ASYM-2 & 1.429 & 275.50 \\
\hline ASYM-3 & 1.429 & 347.20 \\
\hline
\end{tabular}

Table 23: Spectral Displacement in Y-Direction.

\begin{tabular}{|c|c|c|}
\hline Model & $\begin{array}{c}\text { Period } \\
\text { in sec }\end{array}$ & $\begin{array}{c}\text { Spectral } \\
\text { Displacement } \\
\text { in mm }\end{array}$ \\
\hline SYM & 1.429 & 31.30 \\
\hline ASYM-1 & 1.429 & 95.70 \\
\hline ASYM-2 & 1.429 & 340.60 \\
\hline ASYM-3 & 1.429 & 579.60 \\
\hline
\end{tabular}




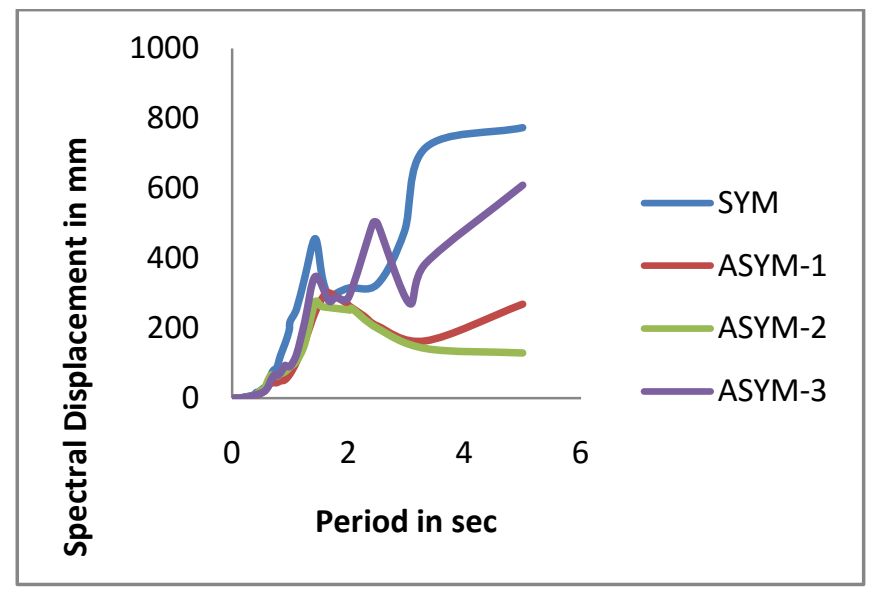

Fig 19: Spectral Displacement in X-Direction.

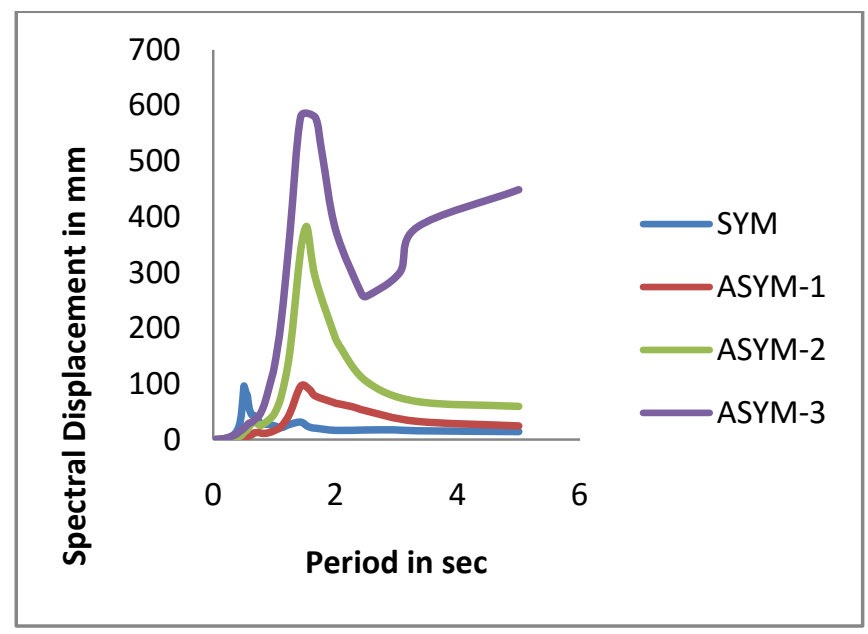

Fig 20: Spectral Displacement in Y-Direction.

From Table 22, it can be observed that the Asymmetrical-1 and Asymmetrical-2 are behaving as flexible structure, and in the case of Symmetrical and with the highest percentage of eccentricity in Asymmetrical-3 structures are behaving as more rigid in nature causing the torsional effect on the structure which makes the structure to undergo huge displacement within in a short period of time in X-direction. From Table 23, it can be observed that the Symmetrical and Asymmetrical-1 are behaving as flexible structure, as the eccentricity increases Asymmetrical-2 and Asymmetrical-3 structures are behaving as more rigid in nature causing the torsional effect on the structure which makes the structure to undergo huge displacement within in a short period of time in Y-direction.

From the above inference it can be observed that the Symmetrical structure is performing well in $\mathrm{Y}$-direction, Asymmetrical-1 in Y-direction, and Asymmetrical-2 and Asymmetrical-3 is behaving as a rigid structure in both the directions.

\subsubsection{Spectral Acceleration v/s Period.}

This represents the maximum or peak response of a single degree of freedom system to a particular seismic input as a function of natural frequency. The tables represents the spectral acceleration experienced by the SYM and ASYM structures in $\mathrm{X}$ and $\mathrm{Y}$-directions and its corresponding graphs.

Table 24: Spectral Acceleration in X-Direction.

\begin{tabular}{|c|c|c|c|}
\hline Model & $\begin{array}{c}\text { Period } \\
\text { in sec }\end{array}$ & $\begin{array}{c}\text { Spectral } \\
\text { Acceleration } \\
\text { in } \mathrm{m} / \mathrm{sec}^{2}\end{array}$ & $\begin{array}{c}\text { Spectral } \\
\text { Displacement } \\
\text { in mm }\end{array}$ \\
\hline SYM & 1.429 & 8.940 & 456.20 \\
\hline ASYM-1 & 1.429 & 4.790 & 245.00 \\
\hline ASYM-2 & 0.667 & 5.968 & 65.00 \\
\hline ASYM-3 & 0.429 & 6.768 & 12.00 \\
\hline
\end{tabular}

Table 25: Spectral Acceleration in Y-Direction.

\begin{tabular}{|c|c|c|c|}
\hline Model & $\begin{array}{c}\text { Period } \\
\text { in sec }\end{array}$ & $\begin{array}{c}\text { Spectral } \\
\text { Acceleration } \\
\text { in } \mathrm{m} / \mathrm{sec}^{2}\end{array}$ & $\begin{array}{c}\text { Spectral } \\
\text { Displacement } \\
\text { in } \mathrm{mm}\end{array}$ \\
\hline SYM & 0.493 & 14.294 & 88.40 \\
\hline ASYM-1 & 1.429 & 7.671 & 95.70 \\
\hline ASYM-2 & 1.429 & 11.633 & 340.60 \\
\hline ASYM-3 & 1.429 & 11.169 & 579.60 \\
\hline
\end{tabular}

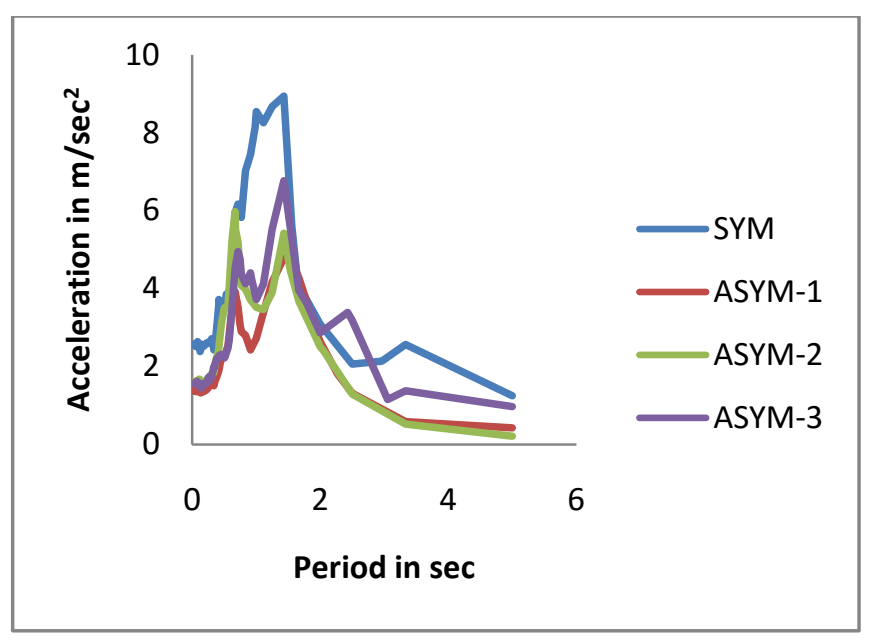

Fig 21: Spectral Acceleration in X-Direction.



Fig 22: Spectral Acceleration in Y-Direction. 
From Table 24, it can be observed that the Symmetrical structure is behaving as a flexible structure, as the eccentricity increases in Asymmetrical-1 structure for a less acceleration compared to Symmetrical Structure it has a displacement of $245.00 \mathrm{~mm}$ causing a brittle failure of the structure, with the further increase in eccentricity in Asymmetrical-2 it experiences a greater acceleration at very less period of time causing failure of the structure with a displacement of $65.00 \mathrm{~mm}$ and with further increase in eccentricity in Asymmetrical-3 it experiences a greater acceleration and displacement compared to all the structure causing the structure to fail at the earliest in X-direction.

Also from Table 25, it can be observed that the Symmetrical structure can with stand more acceleration with a displacement of $88.40 \mathrm{~mm}$, as the eccentricity increases in Asymmetrical-1 structure for an acceleration compared to Symmetrical Structure it has a displacement of $95.70 \mathrm{~mm}$ behaving as flexible structure, with the further increase in eccentricity in Asymmetrical-2 it experiences a greater acceleration at same period of time causing the failure of the structure, and with further increase in eccentricity in Asymmetrical-3 it experiences a greater acceleration and huge displacement compared to all the structure causing the structure to fail at the earliest.

From the above, it can be observed that the Symmetric structure is performing well in Y-direction, Asymmetrical-1 is performing well in Y-direction, Asymmetrical-2 is performing well in Y-direction and Aymmetrical-3 is failing at the earliest in both the directions.

\section{CONCLUSIONS}

\subsection{Pushover Analysis:}

The column orientation has a great effect on the lateral resisting capacity of the structures, Symmetrical structure shows greater capacity than all the Asymmetric structures, the structures are behaving ductile in lateral displacement up to an eccentricity of $14 \%$ of the base width, further increase in eccentricity makes the structure to behave as brittle, ductility of the building depends on the eccentricity of the structure, early collapse of the structure is observed in Asym-3 model having highest eccentricity which makes it more brittle, minimum storey drifts are seen in Sym, Asym1 and Asym-2 structure with less amount of eccentricity and Asym-3 with highest eccentricity greater drifts can be seen and the target displacement is least for the Sym structure, Asym-1 and Asym-2 with less eccentricity and increases in Asym-3; also it is very less in the direction of orientation of the columns in Symmetrical structure.

\subsection{Non-Linear Time History Analysis:}

Maximum Storey Displacement is very less in the case of Sym structure and slightly higher for Asym-1, Asym-2 and greater displacement is observed in Asym-3 structure which makes the structure to collapse earlier. Maximum Lateral Displacement is less in case of Sym Structure, Asym-1 and Asym-2 structure particularly in the direction of less percentage of eccentricity of the same structure and in Asym-3 huge displacements are seen. Maximum Spectral Displacement is observed in Asymmetrical-3 structure with highest eccentricity.

Maximum Spectral Acceleration with corresponding displacement is observed in the structure with greater eccentricity and less in Symmetrical structure particularly in the direction of orientation of the columns.

\subsection{Overall Outcome of the Study:}

Seismic Performance of the structure depends on mainly on the eccentricity between centre of mass and centre of rigidity of that structure. Structures are performing well in the direction of orientation of the columns. Greater displacement is seen the structure with highest eccentricity. Structure with highest eccentricity collapse earlier than the symmetrical and with minimum eccentricity. The percentage of eccentricity of the structure should be limited to $14 \%$. Symmetrical, Asymmetrical-1 and Asymmetrical-2 structures are performing well in the direction with less eccentricity compared to that of the same structure in the other direction and in the direction of orientation of the columns in Symmetrical structure considered. Non-Linear Time History Analysis gives better and actual behavior of the structure subjected to Seismic load compared to that of Non-Linear Static Analysis (Pushover Analysis).

\section{REFERENCES}

[1] Dr.Naresh Kumar B.G and Avinash Gornale [2012], "Seismic Performance Evaluation of Torsionally Asymmetric Structures", International Journal of Science and Engineering Research, Volume 3, Issue 6, ISSN 2229-5518 (Department of Civil Engineering, Maharaja Institute of Technology, Mysore).

[2] Dr. Naresh KumarB.G, AvinashGornale and Abdullah Mubashir [2012] "Seismic Performance Evaluation of RC-Framed Buildings- An Approach to Torsionally Asymmetric Buildings", IOSR Journal of Engineering, ISSN: 2250-3021, Vol 2, Issue 7 (July 2012), PP 01-12, (Department of Civil Engineering, Maharaja Institute of Technology, Mysore).

[3] Ozlem Cavdar and Alemdar Bayraktar [2011], "Pushover and Non-Linear Time History Analysis Evaluation of a RC building collapsed during the Van (Turkey) Earthquake on Oct 23, 2011", Nat Hazards, DOI 10.1007/s 11069-013-0835-3 (Department of Civil Gumushane University and Karadeniz Technical University).

[4] Rama Raju K, Cinitha A and Nagesh R Iyer [2012], "Seismic Performance Evaluation of Existing RC Buildings Designed as per Past Codes of Practice", Sadhana Vol. 37, Part 2, page no 281-297.

[5] Dr.Tande, S.B.Kadam and Sandesh N. Suryawanshi [2014], "Torsional Behaviour of Asymmetrical Buildings in Plan under Seismic Forces”, Vol 2 Issue 4, July 204, PP170-176, ISSN 
2349-4395 (Print) and ISSN 2349-4409(Online), (Department of Applied Mechanics, Walchand College of Engineering, Engineering, Sangli).

[6] G S Hiremath and Kushappa M Kabade,[2014] "Comparative study of Performance Based Plastic Design of RC and Composite Moment Resisting Frames Based on Inelastic Response Analysis", Vol no 3, Issue 8, IJARSE and ISSN-23198354(E).

[7] PankajAgarwal and Manish Shirkhande, "Earthquake Resistant Design of Structures", page no 197, 203 [Text book].

[8] Federal Emergency Management Agency, "Prestandard and Commentary for the Seismic Rehabilitation of buildings", Report no. FEMA 356, 2000, Washington, D.C.

[9] Bureau of Indian Standards, "Criteria for Earthquake Resistant Design of Structures." IS1893 (Part I): 2002, New Delhi.

[10] ATC 40. (1996). "Seismic Evaluation and Retrofit of Concrete Buildings: Vol. I', Applied Technology Council, USA.

\section{BIOGRAPHIES:}
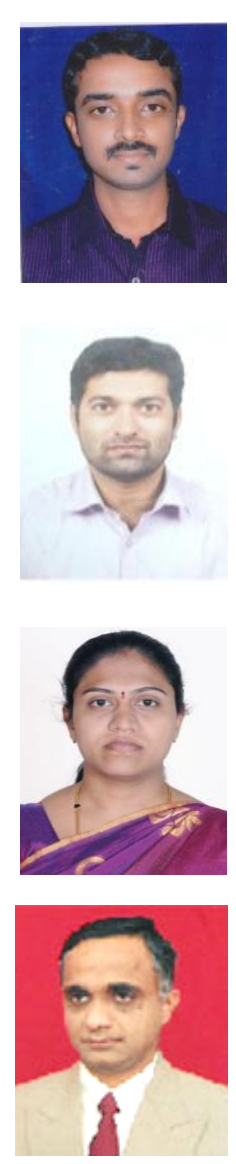

Mr. Nischith $S$, is a Final Year PG Student, pursuing his Master of Technology in CAD Structures, from Sri Siddhartha Institute of Technology, Tumkur District, Karnataka, India

Mr. Avinash Gornale BE, M.Tech is working as an Assistant Professor in department of civil engineering in Maharaja Institute of Technology, Mysore, Karnataka. His areas of research interest include Earthquake engineering and Performance Evaluation.

Mrs. Sowjanya G. V BE, M.Tech is working as an Assistant Professor in department of civil engineering in Sri Siddhartha Institute of Technology, Tumkur District, Karnataka, India.

Dr. B G Naresh Kumar B.E., M.E., Ph.D. working as Prof and Principal in Maharaja Institute of Technology, Mysore, Karnataka. ME \&Ph.D. from IIT Kharagpur. In the past he worked as Legal Advisor for AICTE, New Delhi. 